\title{
Design of a Dual-Band Microstrip Patch Antenna for GPS,WiMAX and WLAN.
}

\author{
Amit Kumar ${ }^{1}$,Sachin Kumar,Prof.P.R.Chadha ${ }^{1}$ \\ ${ }^{\prime}$ (Dept.of ECE,Delhi Technological University,Delhi,India)
}

\begin{abstract}
The A multi band microstrip patch antenna has been designed for GPS, WiMAX and WLAN applications. The proposed antenna is designed by using substrate of RT duroid having permittivity of about 2.2 and loss tangent of 1.The substrate is having thickness of $6 \mathrm{~mm}$ at which a trapezoidal patch antenna with $V$ slot has been introduced in this paper. The designing results like S11 parameter return loss, VSWR and field pattern is plotted successfully. The obtained result is having a two band resonance with S11 less then -1OdB and VSWR less than 2.

So a dual band trapezoidal microstrip patch antenna has been designed and all results are plotted.Simmulating software used is IE3D.
\end{abstract}

Keywords - V-shape slot, RT duroid, Dual band, WLAN, WiMAX,

\section{INTRODUCTION}

Microstrip antenna is the ideal choice for wireless an such typed application due to low profile, light weight, conformal shaping, low cost ,simplicity of manufacturing and easy integration to circuit[1].however, conventional microstrip patch antenna suffers from very narrow bandwidth, typically about $5 \%$ bandwidth with respect to the central frequency. there are numerous and well-known method to increase the bandwidth of antennas, including increase of the substrate thickness, the use of a low dielectric substrate, the use of multiple resonators, and the use of slot antenna geometry[2],[3].

Wireless local area networks (WLAN) are widely used worldwide. The 802.11a standard uses the 5$\mathrm{GHz}$ band which is cleaner to support high-speed WLAN. However, the segment of frequency band used varies from one region of the world to another[6][7]. Dual frequency microstrip antennas with a single feed are required in various radar and communication systems, such as global positioning system (GPS), WiMAX,WLAN etc[1].

These communication system applications include fixed broadband local multipoint communication services, small mobile units, laptops and remote-sensing devices [2]. Also, bandwidth should be further enhanced in order to increase the information transfer rate, without sacrificing the performance[4]. There are lots of communication schemes that make use of the large operational bandwidth [8][9]. For example, the Orthogonal frequency-division multiplexing (OFDM) scheme transmit and receive signals with a number of frequency components [3]-[5]. Another example is the transmission of broadband pulse. radiating edge.

In this paper, we design a trapezoidal patch with $\mathrm{V}$-shaped antenna which works as a dual frequency. First resonance frequency f1 centered at $3.5 \mathrm{GHz}$ frequency is due to its patch itself. Second resonant frequency $\mathrm{f} 2$ is due to V-shape slot, which is centered at $5.0 \mathrm{GHz}$.

\section{ANTENNA STRUCTURE}

The configuration of proposed antenna is shown in figure 1. The antenna consist of a trapezoidal microstrip patch with $\mathrm{V}$-shaped slot, support on a grounded dielectric sheet of thickness $\mathrm{h}$ and dielectric constant $\varepsilon$ r. The trapezoidal patch has an upper side of length L1, base of trapezoidal patch of length L2 and height of trapezoidal patch of length W1, W2. V-shape slot has a length of L3, L4 and a width of W3, W4 which is loaded on trapezoidal patch. The feed point is located at the central line of the patch, with a distance of $d f(X . y)$ from the bottom edge of trapezoidal patch.The dimension of trapezoidal patch with V-shape slot are tabulated in table 1. 


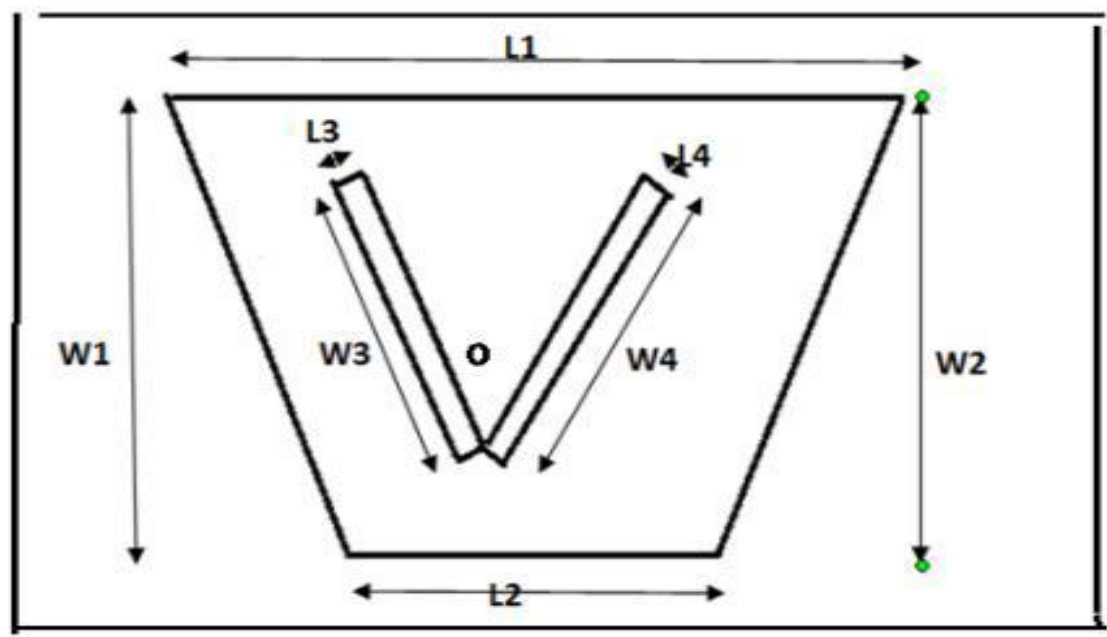

Fig.1: Geometry of proposed antenna

Table 1. Dimension of proposed antenna

\begin{tabular}{|l|l|l|}
\hline S.no & Parameter & Value(mm) \\
\hline 1 & L1 & 30 \\
\hline 2 & L2 & 26 \\
\hline 3 & W1,W2 & 21.04 \\
\hline 4 & L3,L4 & 0.5 \\
\hline 5 & W3,W4 & 1.5 \\
\hline 6 & $\varepsilon$ r & 2.2 \\
\hline 7 & h & 6 \\
\hline
\end{tabular}

The proposed antenna is designed and simulated by using IE3D software. All the proposed design parameters are calculated by using conventional formula for patch antenna design process.

\section{DESIGN RESULTS}

In this section, the simulated results of various parameters like VSWR, Return loss, input impedance and radiation characteristics of proposed antenna are presented and discussed. The simulated results are obtained using IE3D Simulator.

\section{A. SII PARAMETER and VSWR}

The simulated result for the return loss less than $-10 \mathrm{~dB}$ is shown in figure 2. From simulated result we get dual band. Based on a $-10 \mathrm{~dB}$ return loss, $4 \%$ impedance bandwidth is obtained at first resonant frequencies f1 in the frequency range (3.41-3.57) GHz and $15.6 \%$ impedance bandwidth is obtained at second resonance frequencies in the frequency range of $4.75-5.53 \mathrm{GHz}$.

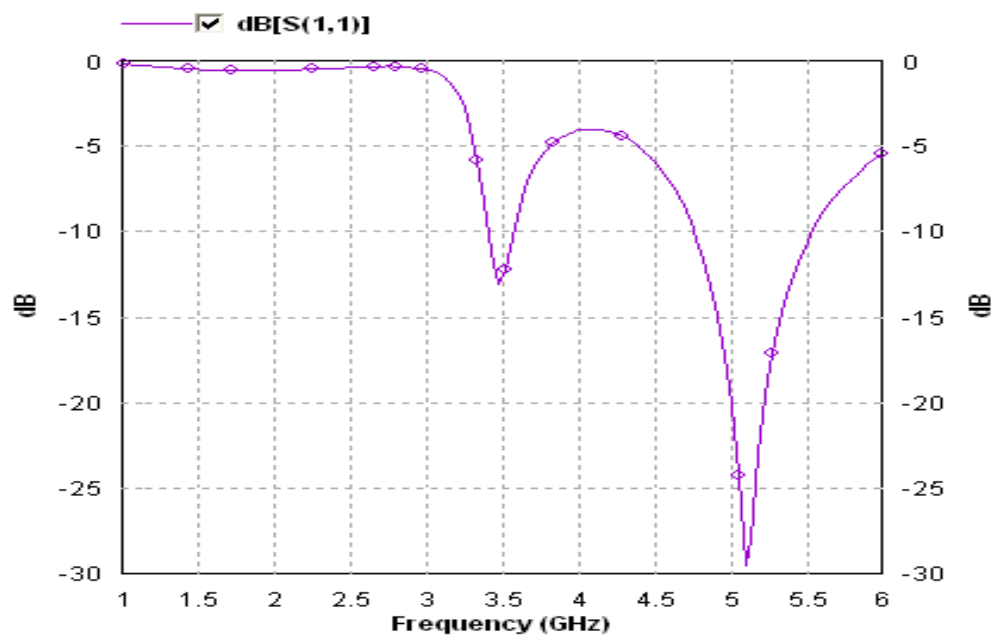

Fig. 2: Return loss 
VSWR plot shows that the VSWR occur at first resonant frequency is 1.66 and second resonant frequency is 1.07. This depict that there is good impedance matching between probe-fed microstrip transmission line and the trapezoidal radiating element.

\section{B. Input impedance}

The simulated result for the antenna input impedance is plotted in figure 4. It is shown that the real part of the input impedance at first resonant frequency fl oscillates around $74.83 \Omega$ with frequency while the imaginary part of the input impedance at resonant frequency oscillates around $0 \Omega$ with frequency.

At second resonant frequency $\mathrm{f} 2$, the real part of the input impedance at resonant frequency oscillates around $50 \Omega$ with frequency while the imaginary part of the input impedance at resonant frequency oscillates around $0 \Omega$ with frequency. Hence, from the graph it is clear that there is proper matching occur at both resonant frequencies

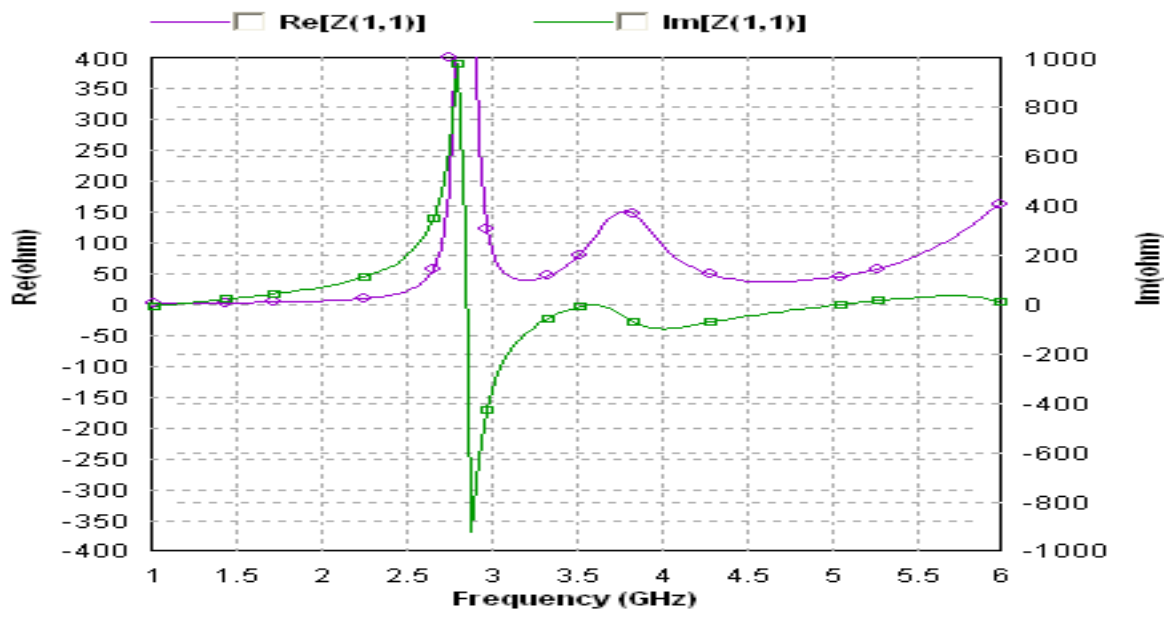

Fig. 4: Real part and imaginery part of input impedance

\section{Radiation pattern}

From figure below Shows the measured radiation pattern at first resonant frequency $3.5 \mathrm{GHz}$. it can be observed that in the $\phi=0$ plane, the cross polarization is $-13 \mathrm{db}$ below the co polarization above the ground plane. In the $\phi=90$ plane, the cross polarization is $-19.3 \mathrm{~dB}$ below the co polarization level.

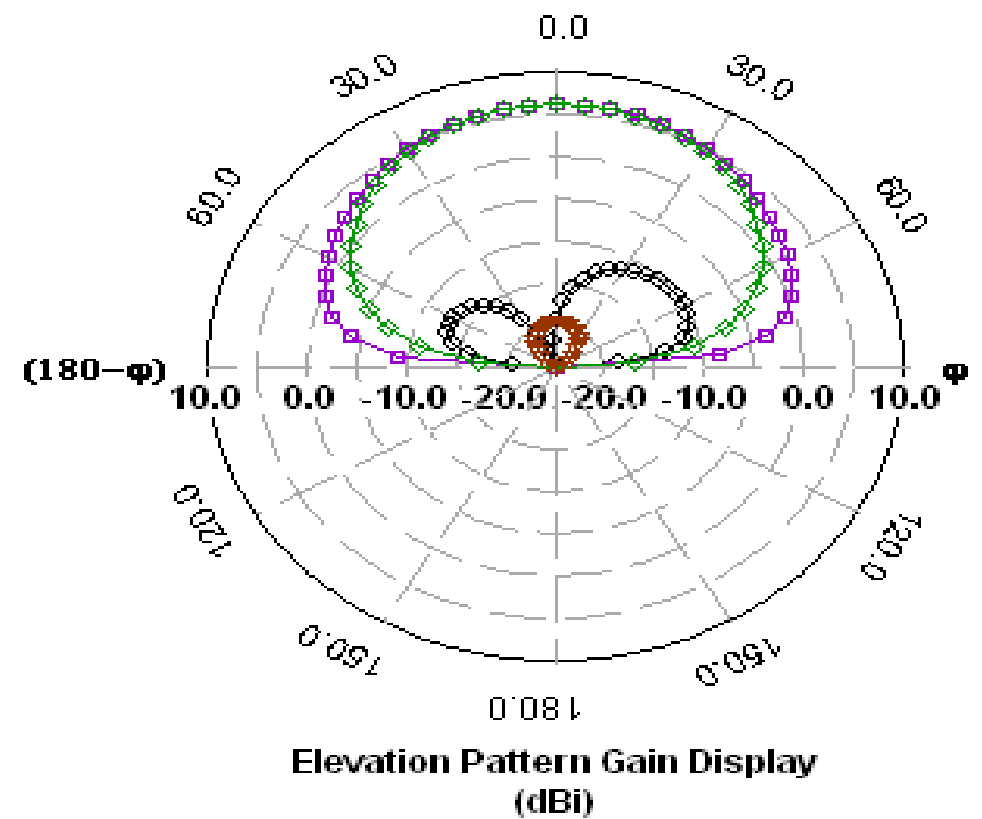

Fig. 5: Radiation pattern at $3.5 \mathrm{GHz}$ 
Table 2. Simulated data

\begin{tabular}{|l|l|l|}
\hline Resonant frequency & $\mathrm{F} 1$ & $\mathrm{~F} 2$ \\
\hline Centre frequency & $3.5 \mathrm{GHz}$ & $5 \mathrm{GHz}$ \\
\hline bandwidth & 4.95 & $15.6 \%$ \\
\hline Frequency range & $(3.41-3.57) \mathrm{GHz}$ & $(4.75-5.53) \mathrm{GHz}$ \\
\hline Return loss & $-12.8 \mathrm{~dB}$ & $-29.37 \mathrm{~dB}$ \\
\hline VSWR & 1.66 & 1.07 \\
\hline
\end{tabular}

\section{CONCLUSION}

The dual frequency and wide-band operation of a trapezoidal patch with $\mathrm{V}$-shaped slot have been studies and simulated. The proposed antenna is compact, occupies small volume and has simple structure compared to other antenna design. The antenna offer a 2:1 VSWR bandwidth of $4 \%$ from frequency range (3.41-3.57) GHz at first resonant frequency which cover $3.5 \mathrm{GHz}$ band WiMAX applications. second resonant frequency cover the WLAN(5.15-5.35) band application with impedance bandwidth 0f 15.6\%.the simulated return loss, VSWR, radiation pattern and gain showed well performance.

\section{REFERENCES}

[1] W.He, R.Jin, and J.Gerg, "E-shape patch with wideband \& circular polarisation for millimetre wave communication," IEEE Trans. Antenna Propag.,vol.56,no.3, pp.893-895,2008.

[2] K.L Lau, K.M. Luk, and K.L.Lee, "Design of a circularly-polarized vertical patch antenna,"IEEE Trans. Antenna Propag.,vol.54, no.3, pp.1332-1335,2006.

[3] D.M Pozar \& D.H Schauber, "Design of Microstrip antennas and arrays, New York: IEEE Press, 1995

[4] Sudhir Bhaskar \& Sachin K. gupta, "Bandwidth improvement of microstrip patch antenna using H- shaped patch", Publication in the international Journal of engineering Research and application", vol.2, Issue 1, pp.334-338, Jan-Feb 2012.

[5] Wong KL and Hsu WS, "broadband triangular microstrip antenna with U shape slot" Electron lett(UK),33(1997)2085.

[6] Sharma V, Sharma V K,Bhatnager D, Saini J.S, "Compact dual frequency wide band circular patch antenna with U-slot," Proc of IEEE International symposium on Antenna and propoagation and USNC/URSI National Radio Science Meeting, (IEEE,USA), 1979,1

[7] S. W. Lee, S. M. Park, N. Kim, S. W. Park, and S. Y. Rhee, "Design and SAR Measurement of the Trapezoidal Shape Antenna," Progress In Electromagnetics Research C, Vol. 26, 127-136, 2008.

[8] Amit Kumar,P.R.Chadha, Microstrip Antenna for WLAN Application Using Probe Feed, IOSR-JECE, Volume X, Issue X (Jan. Feb. 2013)

[9] Prof. P.R. Chadha, Amit kumar, Ractangular Microstrip Patch Antenna Designfor WLAN Application Using Probe Feed. IJETAE, Volume 2, Issue 12, December 2012 